\title{
Bone Marrow Mesenchymal Stem Cells From Healthy Donors and Sporadic Amyotrophic Lateral Sclerosis Patients
}

\author{
Ivana Ferrero,* Letizia Mazzini, $\dagger$ Deborah Rustichelli,* Monica Gunetti,* Katia Mareschi,* \\ Lucia Testa, $\dagger$ Nicola Nasuelli, $\uparrow$ Gaia Donata Oggioni, $\uparrow$ and Franca Fagioli* \\ *Department of Pediatrics, "Regina Margherita Children's Hospital”, University of Turin, Turin, Italy \\ $\dagger$ Department of Neurology, "Maggiore della Carità Hospital”, University of Eastern Piedmont, Novara, Italy
}

\begin{abstract}
Amyotrophic lateral sclerosis (ALS) is a fatal neurodegenerative disease lacking effective therapies. Cell replacement therapy has been suggested as a promising therapeutic approach for multiple neurodegenerative diseases, including motor neuron disease. We analyzed expanded mesenchymal stem cells (MSCs) isolated from sporadic ALS patients and compared them with MSCs isolated from healthy donors. MSCs were isolated from bone marrow by Percoll gradient and maintained in culture in MSC Medium until the third passage. Growth kinetics, immunophenotype, telomere length, and karyotype were evaluated during in vitro expansion. Osteogenic, adipogenic, chondrogenic, and neurogenic differentiation potential were also evaluated. No morphological differences were observed in the MSCs isolated from donors or patients. The cellular expansion potential of MSCs from donors and patients was slightly different. After three passages, the MSCs isolated from donors reached a cumulative population doubling higher than from patients but the difference was not statistically significant. No significant differences between donors or patients were observed in the immunophenotype analysis. No chromosomal alteration or evidence of cellular senescence was observed in any samples. Both donor and patient MSCs, after exposure to specific conditioning media, differentiated into adipocytes, osteoblasts, chondrocytes, and neuron-like cells. These results suggest that extensive in vitro expansion of patient MSCs does not involve any functional modification of the cells, including chromosomal alterations or cellular senescence. Hence, there is a good chance that MSCs might be used as a cell-based therapy for ALS patients.
\end{abstract}

Key words: Amyotrophic lateral sclerosis; Mesenchymal stem cells; In vitro expansion; Cellular therapy

\section{INTRODUCTION}

Amyotrophic lateral sclerosis (ALS) is a rapid and progressive disease characterized by the selective degeneration of motor neurons that manifests as a linear decline in muscular function, which eventually leads to paralysis, speech deficits, and dysphagia. Within 2 to 5 years of clinical onset, death, due to respiratory failure, occurs (24). For the vast majority of ALS cases, the factors triggering focal initiation and then the spread of motor neuron degeneration in sporadic ALS remain to be elucidated and there is no drug currently available to cure human motor neuron disease.

Stem cell transplantation might represent a potential therapeutic strategy in ALS (20). Bone marrow stem cell transplantation provides positive clinical outcomes in different animal models of central nervous system diseases. Transplanted stem cells might exert beneficial ef- fects by improving the microenvironment (4), by producing neurotrophic factors (9), or by a nonneuronal environmental change achieved by bone marrow (BM) transplantation (5).

The use of mesenchymal stem cells (MSCs) as a cell therapy to repair central nervous system damage is supported by the ability of these cells to differentiate into multiple mesenchymal lineages under controlled in vitro conditions (23). These cells proliferate in culture, acquiring an attached, well-spread morphology, with a consistent set of marker proteins on their surface, and can differentiate into neurons and glial cells both in vitro $(11,26,31,32)$, as recently also reported by our group $(16)$, and in vivo $(2,10,29)$. Recent studies demonstrate that the potency of MSCs may also be due to the production of neurotrophic factors, which promote neuronal survival (6).

Our preliminary data seem to demonstrate that autol- 
ogous MSCs transplanted into the spinal cord of a wellmonitored group of ALS patients are safe and well tolerated (17-19).

This study was aimed at analyzing whether MSCs expanded from donors and from sporadic ALS patients showed any differences concerning cell growth, immunophenotype, osteogenic, adipogenic, chondrogenic, and neurogenic differentiation potential, telomere length, and karyotype modifications during in vitro expansion.

\section{MATERIALS AND METHODS}

\section{Study Subjects}

Eighteen healthy Caucasian donors (4 men and 14 women), who underwent BM collection for a related patient, and 24 patients (13 men and 11 women) affected by sporadic ALS enrolled in a study approved by the Italian Institute of Health and by the Ethical Committee of the Piedmont Region were analyzed. Inclusion criteria were: diagnosis of definite ALS according to the El Escorial revised criteria (3), mild to severe functional impairment at the spinal level, no or mild signs of bulbar involvement, no signs of respiratory failure. Patients and controls were excluded if they had evidence of any concurrent illness or were receiving any medications that could affect bone. Standard therapies were used throughout the study.

The severity of the disease was evaluated by means of ALS Functional Rating Scale (FRS) (30), Norris score (22), and Forced Vital Capacity.

\section{Bone Marrow}

$\mathrm{BM}$ was collected from the iliac crest under epidural anesthesia according to the standard procedure (1). Both donors and patients gave their informed consent to participate in the study.

\section{Isolation of MSCs}

Donor BM cells were obtained from the unfiltered BM collection bag (Baxter Healthcare Corporation, IL, USA), containing a few milliliters of BM, which was normally discarded before the BM infusion. The bag was washed three times with phosphate-buffered saline (PBS) $1 \times$ (Cambrex Biosciences, Verseviers, Belgium) and the cells were collected at $900 \times g$ for $15 \mathrm{~min}$. A median number of $885 \mathrm{ml}$ (range 612-1,420) of BM was harvested from patients and centrifuged at $900 \times g$ for $15 \mathrm{~min}$ to discard the anticoagulant medium. Donor and patient cells were then layered on a Percoll (Sigma Aldrich, St. Louis, MO, USA) gradient (density: 1.073 $\mathrm{g} / \mathrm{ml}$ ) and centrifuged at $1100 \times g$ for $30 \mathrm{~min}$, according to a previously reported method (14). The cells in the interphase were collected, washed twice with PBS $1 \times$ $(200 \times g$ for $10 \mathrm{~min})$, and seeded at a density of $800,000 / \mathrm{cm}^{2}$ in MSC Medium (Cambrex Bioscience,
Versviers, Belgium) at $10 \%$ of fetal bovine serum (FBS, Cambrex Bioscience) in 75- or $150-\mathrm{cm}^{2}$ T-flasks (Greiner Bio-One $\mathrm{GmbH}$, Frickenhausen, Germany), and maintained at $37^{\circ} \mathrm{C}$ with an atmosphere of $5 \% \mathrm{CO}_{2}$. After 3 days, the nonadherent cells were removed and the cultures refed every 3-4 days. At confluence, after about 15 days, the adhered monolayer was detached with tryp$\sin$ /EDTA (Cambrex Bioscience) for $5 \mathrm{~min}$ at $37^{\circ} \mathrm{C}$, and the trypsin action was blocked with trypsin neutralizing solution (Cambrex Bioscience) for $5 \mathrm{~min}$ at $37^{\circ} \mathrm{C}$. The cells were then seeded at a density of $8,000 / \mathrm{cm}^{2}$ and detached every 7 days for two to three passages in order to expand the isolated cells.

\section{Cellular Expansion Analysis of MSCs}

Cellular expansion growth rate of donor and patient MSCs was evaluated by cell count in a Burker Chamber at each passage and expressed in terms of population doubling (PD) using the formula $\log N / \log 2$, where $N$ is the cell number of the confluent monolayer divided by the initial number of cells seeded, as performed in the Stenderup studies (28).

\section{Cytofluorimetric Analysis of MSCs}

The immunophenotype analysis of adherent cells was performed, at each passage, by flow cytometry analysis. Around $2-5 \times 10^{5}$ cells were stained for 20 min with anti-CD45 fluoroisothyocyanate (FITC) and CD14 phycoerytrin (PE), hematopoietic surface antigens; CD90FITC, a membrane glycoprotein, also called Thy-1, used as a stem cell marker; CD29FITC, the $\beta$ subunit of the fibronectin receptor; CD44PE, receptor-III of extracellular matrix; CD105PE or endoglin; CD166 and CD106, cell adhesion molecules (Becton Dickinson, San Jose, CA, USA), and $0.5 \mu \mathrm{g} / \mathrm{ml}$ of propidium iodide (Sigma Aldrich) for viability analysis. Labeled cells were thoroughly washed with PBS $1 \times$ and were analyzed on an Epics XL cytometer (Beckman Coulter, CA, USA) with the XL2 software program. The percentage of positive cells was calculated using the cells stained with Ig FITC/PE as a negative control.

\section{Evaluation of MSC Telomere Length}

In order to determine senescence during culture, telomere length was analyzed at each passage by Flow Fluorescence In Situ Hybridization (Flow FISH) (25). Two hundred thousand expanded MSCs were labeled with a telomere-specific conjugated $\left(\mathrm{C}_{3} \mathrm{TA}_{2}\right)_{3}$ peptide nucleotide acid (PNA) probe (Perseptive Biosystems, Framingham, MA) and the same number were analyzed as a control without a probe. The same number of hemopoietic stem cells was isolated with an immunomagnetic system using CD34 microbeads conjugated antibody from BM at the moment of collection and used as examples of 
long telomeres. Stained cells were analyzed on a FACS Calibur cytometer (Beckon Dickinson, CA, USA). At the beginning of each experiment, the fluorescence signals from four different populations of FITC-labeled microbeads, ranging from 3,000 to 5,000 molecular equivalents of soluble fluorochrome (MESF) (Quantum ${ }^{\mathrm{TM}} 24$ FITC Premix, Flow Cytometry Corporation, IN, USA), were acquired. The voltage and amplification of the FL1 parameter were set in such a way that blank, 6,288, 12, 25, and 26,904 MESF units per bead corresponded to channel numbers ranging from 10 to 15,150 to 160,450 to 460 , and 800 to 820 , respectively, in the FL1 channel on a linear scale. The resulting calibration curve $(y=$ $0.029 x$ ) was used to convert telomere fluorescence into MESF units in order to compare the experiment results.

\section{Karyotype Analysis of MSCs}

Two hundred thousand MSCs were cultivated overnight in MSC Medium with $100 \mathrm{ng} / \mathrm{ml}$ of Colcemid (Invitrogen Corporation, Grand Island, NY, USA) to obtain a sufficient number of metaphases, and then harvested with trypsin/EDTA. The cells were then lysed with hypotonic $\mathrm{KCl}$ and fixed in a solution of methanol/acetic acid (3:1). Ten metaphases were analyzed after GTG banding using MackType software (Nikon Corporation, Japan). Donor MSCs were analyzed at the second passage, while patient MSCs were analyzed at any culture passage.

\section{In Vitro Differentiation}

To induce osteogenic differentiation, donor and patient MSCs were cultured in $10-\mathrm{cm}^{2}$ petri culture dishes at a density of $8,000 / \mathrm{cm}^{2}$ for 3 weeks in $\alpha$-MEM supplemented with $10 \mathrm{nM}$ dexamethasone, $0.05 \mathrm{mM}$ ascorbic acid, and $10 \mathrm{mM} \beta$-glycerol phosphate (all by SigmaAldrich). The cells were then fixed and permeabilized with acetone/methanol solution (1:1) for $20 \mathrm{~min}$ at $-20^{\circ} \mathrm{C}$ and differentiation was demonstrated by the accumulation of calcium by crystalline hydroxyapatite detection with Von Kossa staining (cells were treated in $0.5 \%$ silver lactate for $25 \mathrm{~min}$, washed in water, and counterstained with nuclear fast red $0.1 \%$ for $5 \mathrm{~min}$; Sigma Aldrich). The accumulation of collagen was evaluated by Masson Thrichrom Goldner staining (Bio-Optica, Milan, Italy). Briefly, the cells were treated with Weigert's iron hematoxylin solution for $10 \mathrm{~min}$ and with picric acid alcoholic solution for $4 \mathrm{~min}$; after washing in water the cells were stained with Ponceau acid fuchsine according to Masson for $4 \mathrm{~min}$, washed in water, and treated with phosphomolybdic acid solution for $10 \mathrm{~min}$. Then, without washing, collagen was evaluated by light green solution according to Goldner for $5 \mathrm{~min}$.

Adipogenic differentiation was obtained by culturing MSCs in $10-\mathrm{cm}^{2}$ petri culture dishes at a density of
$8,000 / \mathrm{cm}^{2}$ in $\alpha$-MEM supplemented with $10 \%$ horse serum and $10 \%$ FBS for 1 week. The cells were then cultured for 3 weeks alternating two different mediums, according to Pittenger's method (23): 1) $\alpha$-MEM supplemented with $1 \mu \mathrm{M}$ dexamethasone, $0.5 \mathrm{mM}$ isobutyl methylxanthine, $10 \mu \mathrm{g} / \mathrm{ml}$ insulin, $100 \mu \mathrm{g} / \mathrm{ml}$ indomethacin (all by Invitrogen Corporation) and 10\% FBS for $72 \mathrm{~h}$, and 2) $\alpha$-MEM with $10 \mu \mathrm{g} / \mathrm{ml}$ insulin (Invitrogen Corporation) for $24 \mathrm{~h}$. After fixing and permeabilizing the cells, adipogenic differentiation was demonstrated by the accumulation of neutral lipid vesicles by Oil Red O staining (Sigma Aldrich). Briefly, cells were stained with Oil Red O $0.5 \%$ for 15 min, washed in water for $10 \mathrm{~min}$, and the nuclei counterstained with Mayers hematoxylin solution for $10 \mathrm{~min}$.

Chondrogenic differentiation was induced by culturing 250,000 MSCs, collected in pellets, in 15-ml Falcon tubes in high glucose Dulbecco's modified Eagle medium (DMEM, Invitrogen Corporation) supplemented with $10 \mathrm{ng} / \mathrm{ml}$ TGF- $\beta 3,100 \mathrm{nM}$ dexamethasone, $50 \mu \mathrm{g} /$ $\mathrm{ml}$ ascorbic acid, $100 \mu \mathrm{g} / \mathrm{ml}$ sodium piruvate, $40 \mu \mathrm{g} / \mathrm{ml}$ prolin, and ITS plus (Invitrogen Corporation) for 3 weeks. The pellets were then included in paraffin and

Table 1. Patients' Characteristics

\begin{tabular}{|c|c|c|c|c|c|}
\hline Patient & Sex & Age & $\begin{array}{c}\text { ALS-FRS } \\
\text { Score }\end{array}$ & $\begin{array}{l}\text { Norris } \\
\text { Score }\end{array}$ & $\begin{array}{c}\text { FVC } \\
(\%)\end{array}$ \\
\hline 1 & $\mathrm{~F}$ & 36 & 31 & 60 & 51 \\
\hline 2 & $\mathrm{~F}$ & 21 & 26 & 77 & 73 \\
\hline 3 & $\mathrm{M}$ & 37 & 37 & 91 & 105 \\
\hline 4 & $\mathrm{M}$ & 29 & 35 & 82 & 80 \\
\hline 5 & $\mathrm{~F}$ & 51 & 31 & 77 & 95 \\
\hline 6 & $\mathrm{M}$ & 60 & 38 & 83 & 117 \\
\hline 7 & M & 32 & 33 & 83 & 77 \\
\hline 8 & $\mathrm{~F}$ & 53 & 33 & 76 & 101 \\
\hline 9 & $\mathrm{M}$ & 47 & 35 & 84 & 104 \\
\hline 10 & $\mathrm{M}$ & 52 & 39 & 94 & 110 \\
\hline 11 & $\mathrm{~F}$ & 58 & 31 & 84 & 125 \\
\hline 12 & $\mathrm{M}$ & 57 & 39 & 93 & 119 \\
\hline 13 & $\mathrm{M}$ & 47 & 36 & 87 & 93 \\
\hline 14 & $\mathrm{M}$ & 41 & 30 & 80 & 104 \\
\hline 15 & $\mathrm{~F}$ & 60 & 26 & 70 & 68 \\
\hline 16 & $\mathrm{~F}$ & 75 & 25 & 70 & 85 \\
\hline 17 & $\mathrm{~F}$ & 48 & 30 & 65 & 82 \\
\hline 18 & $\mathrm{~F}$ & 23 & 16 & 39 & 50 \\
\hline 19 & $\mathrm{M}$ & 32 & 22 & 44 & 81 \\
\hline 20 & $\mathrm{M}$ & 64 & 34 & 75 & 100 \\
\hline 21 & $\mathrm{M}$ & 33 & 13 & 28 & 25 \\
\hline 22 & $\mathrm{~F}$ & 46 & 33 & 75 & 108 \\
\hline 23 & $\mathrm{~F}$ & 45 & 26 & 62 & 53 \\
\hline 24 & M & 36 & 32 & 67 & 100 \\
\hline
\end{tabular}

ALS-FRS: Amyotrophic Lateral Sclerosis-Functional Rating Scale; FVC: forced vital capacity. 

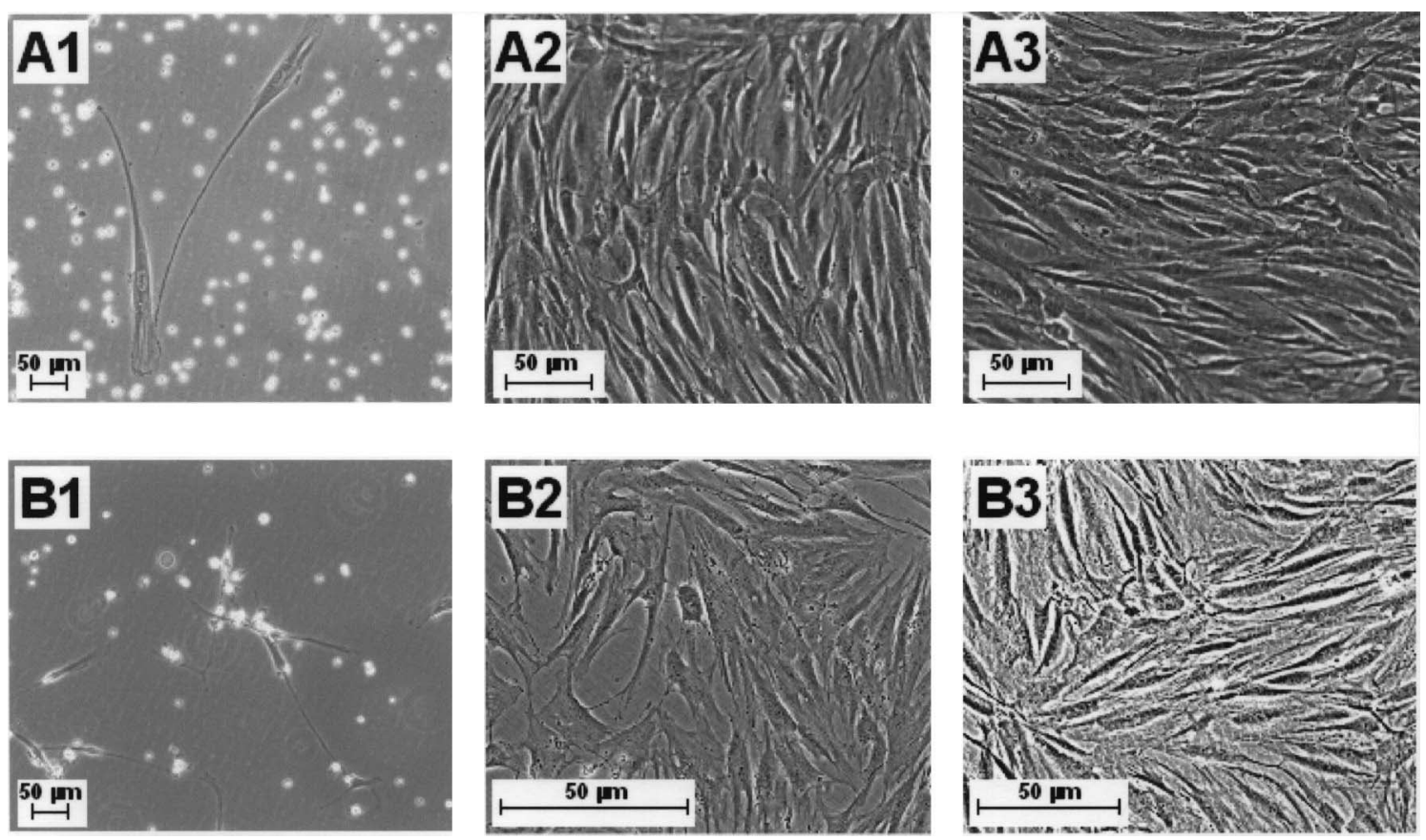

Figure 1. Donor and patient MSC morphology. Phase contrast images of MSC culture after 3 days from the seeding (A1, B1), and at first (A2, B2) and third passage (A3, B3). The upper panels (A) show donor MSCs and the bottom panels (B) patient MSCs. At 3 days of culture the nonadherent cells were removed but a low contamination of hematopoietic cells persisted and a few foci of fibroblastic cells were shown. After 15 days from the seeding (first passage) the presence of nonadherent cells was lower and the formation of the fibroblastic layer was seen until it generated a confluent monolayer. Original magnification $20 \times$.

the cells stained with S-100 antibody $(10 \mu \mathrm{g} / \mathrm{ml}$; Ventana Medical Systems, Tucson, AZ, USA) recognizing S-100 protein localized in chondrocytes.

To induce neural differentiation, we cultured MSCs, for 3 weeks, in $10-\mathrm{cm}^{2}$ petri culture dishes at a density of $8,000 / \mathrm{cm}^{2}$ in Neural Progenitor Maintenance Medium (NPMM) (Cambrex), a maintenance medium for the neural progenitor cells containing basal medium supplemented with recombinant human basic fibroblastic growth factor (hFGF-B), recombinant human epidermal growth factor (hEGF), neural survival factor-1 (NSF-1), and gentamicin $30 \mathrm{mg} / \mathrm{ml}$ and amphotericin $15 \mu \mathrm{g} / \mathrm{ml}$, as previously described (16). Differentiated MSCs were fixed and permeabilized with acetone/methanol solution (1:1) for $20 \mathrm{~min}$ at $-20^{\circ} \mathrm{C}$. Nonspecific binding was blocked with $0.1 \%$ human albumin (HSA) in PBS. The cells were incubated with the primary antibody, then with CY3-coupled anti-mouse (1:1000; Immunological Sciences, Rome, Italy) and FITC-coupled anti-rabbit (1: 500; Southern Biotechnology, Birmingham, AL, USA) secondary antibodies. All incubations were performed for $1 \mathrm{~h}$ at room temperature. Between each step, the cells were washed in 1\% HSA PBS (Cambrex). The cells were reacted with antibodies against neuron specific enolase (NSE) (1:200, Immunological Sciences) and mi- crotubule associated protein (MAP2) (1:50, Chemicon), and positive cells were compared to total cells labeled with 4',6-diamidino-2-phenylindole (DAPI).

\section{Statistical Analysis}

Statistical analysis was performed using a two-way repeated-measures ANOVA to compare the two groups of donors and patients.

\section{RESULTS}

\section{Study Subjects}

Eighteen BM samples collected from healthy donors ( 4 men and 14 women) with median ages of 31 years (20-48 years), and 24 samples collected from ALS patients (13 men and 11 women) with median ages of 47 years (21-75 years) were analyzed. Nine patients showed a severe functional impairment of the lower limbs and were unable to walk while the remaining patients showed a mild functional impairment of the upper and lower limbs. None manifested signs of respiratory failure. The median duration of the disease from diagnosis was 24 months (6-96 months). The main clinical features of patients at the time of recruitment in the study are shown in Table 1. 


\section{MSC Isolation and Morphology}

After Percoll gradient centrifugation a median number of $105 \times 10^{6}(40-267)$ mononuclear cells (MNCs) and $989 \times 10^{6}(84-2,258)$ MNCs were obtained from donors and patients, respectively. During MSC expansion no morphological differences were observed in the MSCs isolated from either donors or from patients: adherent cells were observed in all samples after 3 days of culture and in the following 15 days (first passage) the cells rapidly generated a confluent layer possessing an elongated, fibroblastic shape (Fig. 1). The in vitro expanded MSCs showed no bacterial or fungal contamination.

\section{Cellular Expansion Analysis of MSCs}

Cumulative PD after three passages was $2.3 \pm 1.3$ in the MSCs isolated from donors and $1.5 \pm 1.3$ in patients' MSCs. In terms of absolute numbers, after three passages, we obtained a mean number of MSCs of $8.04 \times$ $10^{6}\left(\mathrm{SD} 9.55 \times 10^{6}\right)$ from donor BM and a mean number of $4.73 \times 10^{6}\left(\mathrm{SD} 5.13 \times 10^{6}\right)$ from patient BM from $1 \times$ $10^{6}$ initial cells. A median of $70 \times 10^{6}$ patient cells (range $7-152 \times 10^{6}$ ) was obtained after three passages. The differences were not statistically significant. No correlation between the cellular expansion potential of MSCs or duration of the disease and functional rating scales was found among the patients.
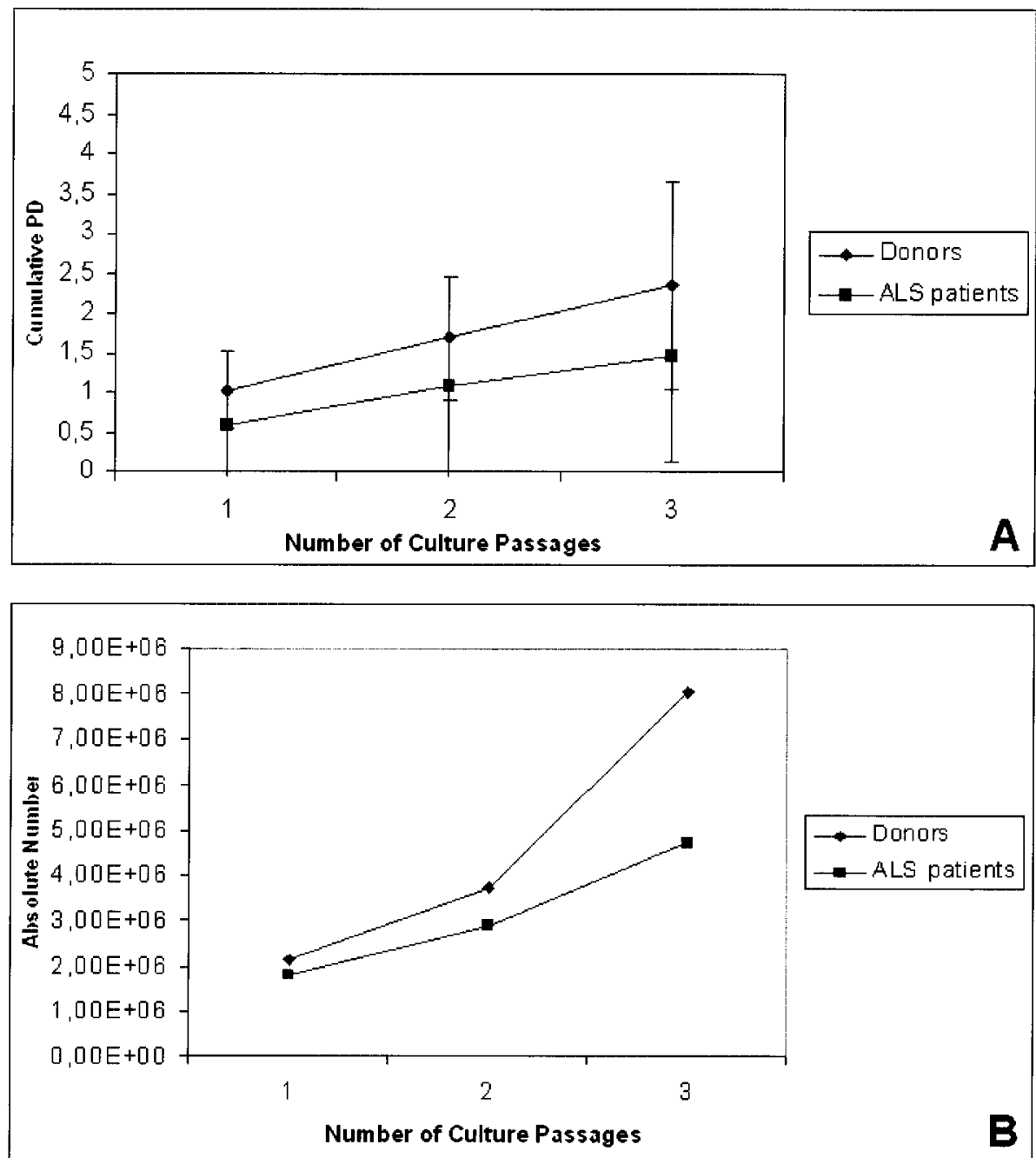

Figure 2. Growth kinetic curves of donor and patient MSC cultures. Growth kinetics of hMSCs isolated from donors and patients during the in vitro expansion from the first to the third passages. The growth rate is expressed as a mean number of cumulative PD (A) and as a mean of absolute number (B) as a function of time in culture. 
Table 2. Median Values (and Ranges) of Antigen Expression of MSCs Isolated From Donors and Patients and Analyzed at Each Passage

\begin{tabular}{|c|c|c|c|c|c|c|c|c|}
\hline & CD45+ & CD14+ & CD90+ & CD106+ & CD29+ & CD44+ & CD166+ & CD105+ \\
\hline \multicolumn{9}{|l|}{ Donors } \\
\hline Passage 1 & $\begin{array}{c}15.45 \% \\
(1.55-29.50)\end{array}$ & $\begin{array}{c}12.67 \% \\
(0.80-32.90)\end{array}$ & $\begin{array}{c}95.85 \% \\
(46.10-98.00)\end{array}$ & $\begin{array}{c}23.20 \% \\
(1.90-75.00)\end{array}$ & $\begin{array}{c}93.00 \% \\
(51.20-98.90)\end{array}$ & $\begin{array}{c}95.40 \% \\
(32.40-99.30)\end{array}$ & $\begin{array}{c}67.95 \% \\
(3.67-78.50)\end{array}$ & $\begin{array}{c}96.10 \% \\
(92.20-98.50)\end{array}$ \\
\hline Passage 2 & $\begin{array}{c}3.05 \% \\
(0.10-11.70)\end{array}$ & $\begin{array}{c}9.08 \% \\
(0.13-29.80)\end{array}$ & $\begin{array}{c}94.60 \% \\
(74.30-99.10)\end{array}$ & $\begin{array}{c}36.80 \% \\
(3.88-96.70)\end{array}$ & $\begin{array}{c}88.30 \% \\
(8.72-97.40)\end{array}$ & $\begin{array}{c}97.70 \% \\
(34.50-99.10)\end{array}$ & $\begin{array}{c}21.30 \% \\
(1.62-61.60)\end{array}$ & $\begin{array}{c}96.70 \% \\
(8.16-99.30)\end{array}$ \\
\hline Passage 3 & $\begin{array}{c}3.59 \% \\
(0.06-6.61)\end{array}$ & $\begin{array}{c}5.69 \% \\
(0.32-6.90)\end{array}$ & $\begin{array}{c}93.70 \% \\
(74.50-99.30)\end{array}$ & $\begin{array}{c}22.05 \% \\
(2.55-63.10)\end{array}$ & $\begin{array}{c}91.20 \% \\
(1.92-97.30)\end{array}$ & $\begin{array}{c}98.90 \% \\
(30.64-99.60)\end{array}$ & $\begin{array}{c}19.00 \% \\
(1.58-57.00)\end{array}$ & $\begin{array}{c}93.90 \% \\
(68.80-99.70)\end{array}$ \\
\hline \multicolumn{9}{|l|}{ Patients } \\
\hline Passage 1 & $\begin{array}{c}12.00 \% \\
(1.20-84.40)\end{array}$ & $\begin{array}{c}7.10 \% \\
(0.07-80.00)\end{array}$ & $\begin{array}{c}77.45 \% \\
(2.50-97.00)\end{array}$ & $\begin{array}{c}30.10 \% \\
(1.30-91.00)\end{array}$ & $\begin{array}{c}75.50 \% \\
(20.00-96.80)\end{array}$ & $\begin{array}{c}93.40 \% \\
(31.00-98.90)\end{array}$ & $\begin{array}{c}15.30 \% \\
(1.00-76.00)\end{array}$ & $\begin{array}{c}77.60 \% \\
(13.76-96.30)\end{array}$ \\
\hline Passage 2 & $\begin{array}{c}8.12 \% \\
(0.93-35.00)\end{array}$ & $\begin{array}{c}8.84 \% \\
(0.00-40.40)\end{array}$ & $\begin{array}{c}78.60 \% \\
(19.60-93.90)\end{array}$ & $\begin{array}{c}40.50 \% \\
(6.40-93.30)\end{array}$ & $\begin{array}{c}82.15 \% \\
(23.47-98.00)\end{array}$ & $\begin{array}{c}93.20 \% \\
(20.70-99.70)\end{array}$ & $\begin{array}{c}16.75 \% \\
(1.50-70.60)\end{array}$ & $\begin{array}{c}87.80 \% \\
(19.31-98.50)\end{array}$ \\
\hline Passage 3 & $\begin{array}{c}5.95 \% \\
(0.00-38.80)\end{array}$ & $\begin{array}{c}2.95 \% \\
(0.00-49.00)\end{array}$ & $\begin{array}{c}90.20 \% \\
(27.50-100.00)\end{array}$ & $\begin{array}{c}44.00 \% \\
(18.00-92.00)\end{array}$ & $\begin{array}{c}92.80 \% \\
(37.20-100.00)\end{array}$ & $\begin{array}{c}94.05 \% \\
(34.80-99.80)\end{array}$ & $\begin{array}{c}24.90 \% \\
(1.00-60.40)\end{array}$ & $\begin{array}{c}91.95 \% \\
(8.00-99.00)\end{array}$ \\
\hline
\end{tabular}

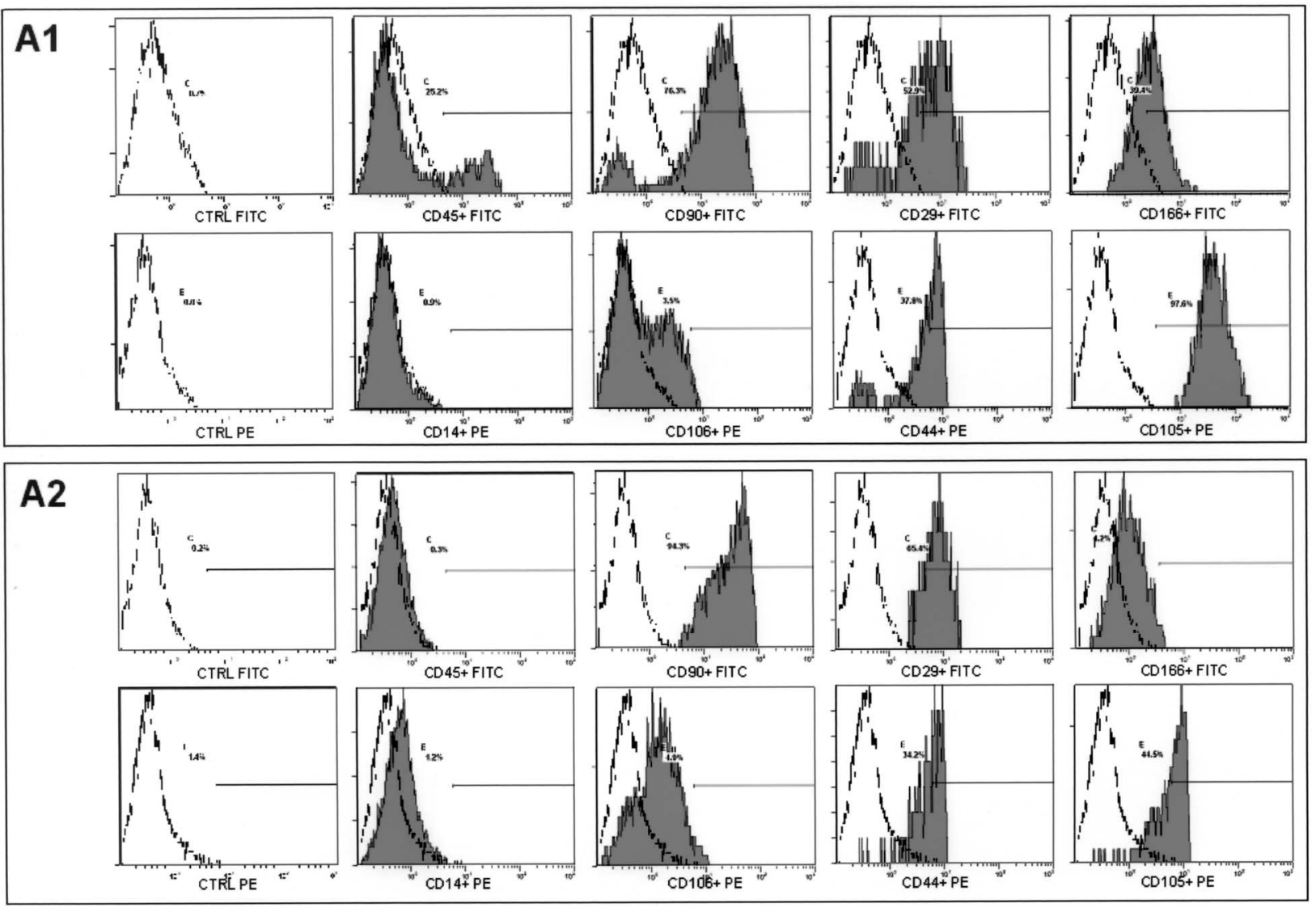

Figure 3. Flow cytometric analysis of donor and patient MSCs at first and third passages. Immunophenotypic features of donor (A) and patient (B) MSCs at the first (A1, B1) and third (A2, B2) passages of in vitro expansion. The percentage of positive cells was calculated using the cells stained with Ig FITC/PE as a negative control. 

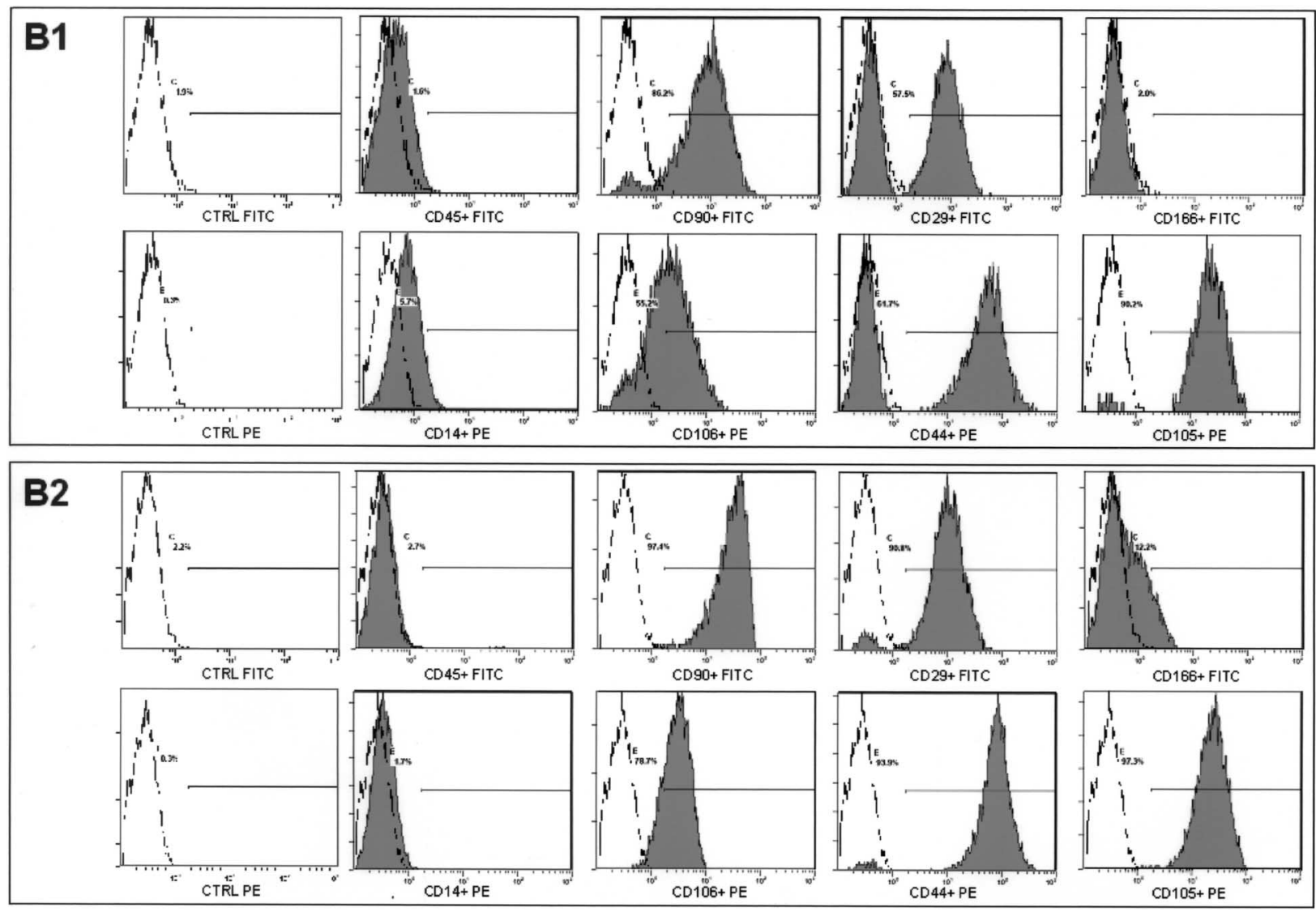

Figure 3. (continued)

The growth curves, expressed in means of cumulative PD and absolute number established for donors and patients, are given in Figure 2.

\section{Cytofluorimetric Analysis of MSCs}

During the expansion time, the cells were analyzed at each passage for the expression of CD45, CD14, CD90, CD29, CD44, CD105, CD166, and CD106 (Table 2). At the first passage the MSC cultures isolated from donors showed a low contamination of hematopoietic cells (CD45 and CD14), while they showed a high expression of CD90, CD29, CD44, and CD105 and a lower expression of CD106 and CD166 adhesion molecules. At the third passage donor MSCs were negative for CD45 and CD14, and expressed high percentages of CD90, CD29, CD44, and CD105 and low levels of CD106 and CD166. MSCs isolated from patients, at the first passage, showed a low contamination of hematopoietic cells (CD45 and CD14) and variable levels of CD90, CD44, CD29, CD106, CD166, and CD105. At the third passage, they expressed lower levels of hematopoietic antigens CD45 and CD14, high levels of CD90, CD29, CD44, and CD105, and lower levels of CD106 and CD166. The immunophenotypic features of donor and patient MSCs are illustrated in Figure 3. Table 2 shows the median values and ranges of the antigen expression of MSCs isolated and analyzed at each passage from donors and patients. No significant differences between donors and patients were observed in the immunophenotype analysis; a slight difference was revealed for CD106, an adhesion molecule, although it was not statistically significant. Figure 4 shows the trend of the antigen expression of MSCs isolated from donors and patients, which were analyzed from the first to the third passage.

\section{Evaluation of Cellular Senescence}

Donor and patient MSCs were analyzed for cellular senescence during the expansion. The mean telomere shortening after three passages was $0.43 \mathrm{~kb}$ in donor MSCs and $0.58 \mathrm{~kb}$ in patient MSCs, as shown in Table 3 ; this difference was not statistically significant.

\section{Karyotype Analysis}

Five donor samples were analyzed at the second passage and no chromosomal alteration was noted. Nor were there any chromosomal alterations at any passages 

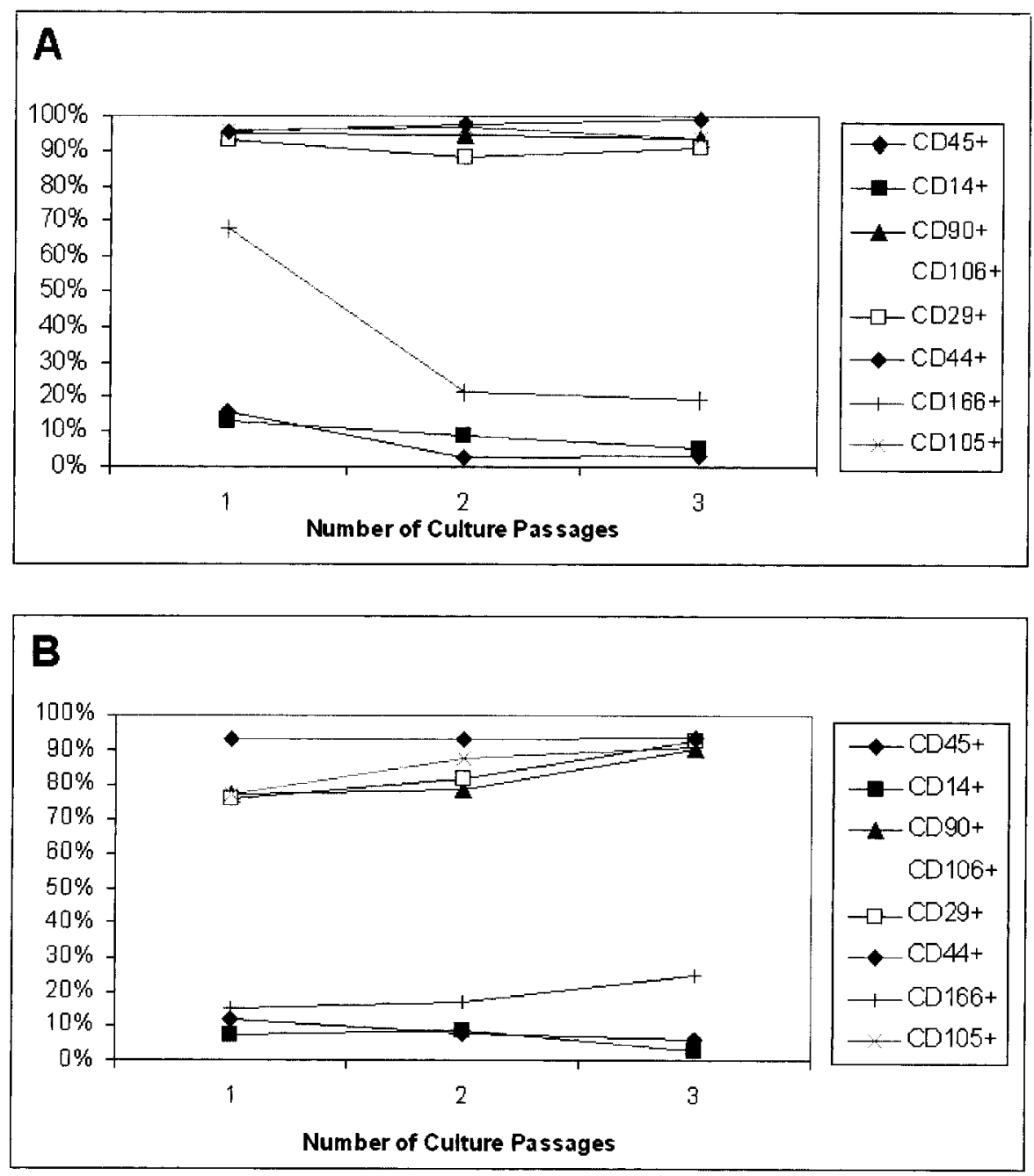

Figure 4. Modulation of median values of antigen expression analyzed at each culture passage during expansion. Cytofluorimetric analysis of MSCs isolated from donors (A) and from patients (B) during the in vitro expansion from the first to the third passage. The percentage of positive cells was calculated using the cells stained with Ig FITC/PE as a negative control.

of all the patient MSCs. The karyotype from one donor and from one patient are given as examples in Figure 5.

\section{In Vitro Differentiation}

Donor and patient MSCs were induced to differentiate into the different lineages. After osteogenic differentiation, donor and patient MSC samples presented some cubical cells with crystals, and calcium ossalates were evaluated by Von Kossa staining (Fig. 6A, B), while the accumulation of collagen was evaluated by Masson Trichrome Goldner (Fig. 6C, D). Adipocytes were revealed as an accumulation of lipid vacuoles: both donor and patient MSCs showed some large, rounded cells with intracytoplasmic vacuoles (Fig. 6E,F), which appeared positive by Oil Red O staining. After 3 weeks with chondrogenic differentiating medium the pellets from donor MSCs and from patient MSCs resulted positive for the presence of S-100 protein (Fig. 6G, H). In

Table 3. Median of Telomere Length and Telomere Shortening of Human MSCs During In Vitro Expansion in Donor and Patient MSCs

\begin{tabular}{lcccc}
\hline & $\begin{array}{c}\text { Passage } \\
1(\mathrm{~kb})\end{array}$ & $\begin{array}{c}\text { Passage } \\
2(\mathrm{~kb})\end{array}$ & $\begin{array}{c}\text { Passage } \\
3(\mathrm{~kb})\end{array}$ & $\begin{array}{c}\text { Shortening: } \\
\text { Pass. 1- } \\
\text { Pass. 3 }(\mathrm{kb})\end{array}$ \\
\hline Donors & 9.83 & 9.74 & 9.40 & 0.43 \\
Patients & 8.52 & 7.63 & 7.94 & 0.58 \\
\hline
\end{tabular}



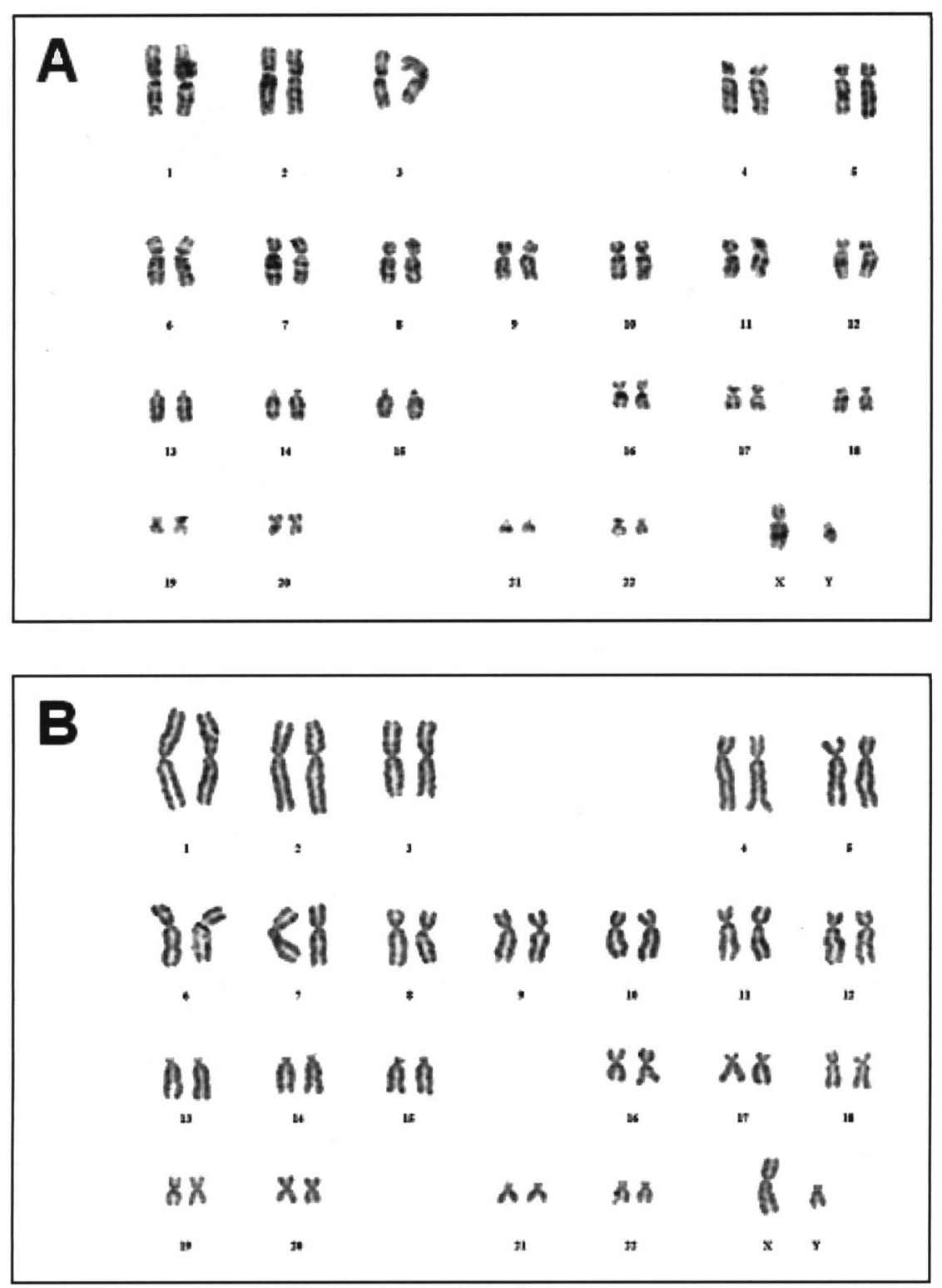

Figure 5. Karyotype of donor and patient MSC cultures. Giemsa-banded karyotype analysis showing chromosomes of MSCs at the third passage. (A) MSCs isolated from one donor. (B) MSCs isolated from one patient.

NPMM, MSCs first aggregated in spheres suspended in the medium and then formed adherent clusters with cells with prominent processes, which resulted positive for NSE (Fig. 6I, J) and MAP-2 (Fig. 6L, M), both in donor and in patient MSCs.

\section{DISCUSSION}

In this work we analyzed the expansion potential of MSCs isolated from the BM of 18 healthy donors and of 24 patients with definite ALS. MSCs were easily isolated from the BM of both healthy donors and patients.
In order to evaluate whether there were any differences between the two groups of MSCs, we analyzed cellular expansion, immunophenotype profile, viability, sterility conditions, cellular senescence, and karyotype. Osteogenic, adipogenic, chondrogenic, and neurogenic differentiation potential was also evaluated. The in vitro cell population was homogeneous with a fibroblasticlike morphology and no hemopoietic cell contamination. The in vitro expanded MSCs showed no bacterial or fungal contamination.

The cellular expansion potential of MSCs from do- 


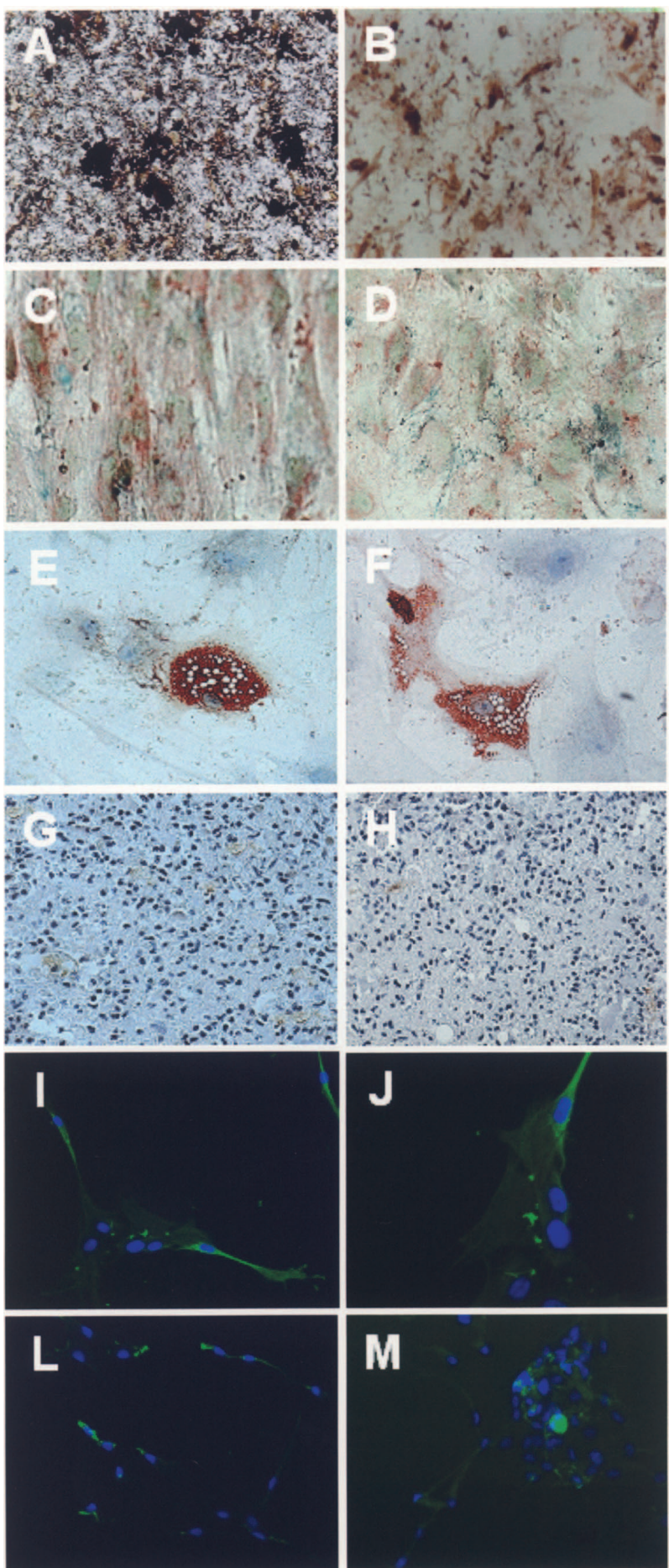

nors and patients was slightly different. After three passages, the MSCs isolated from donors reached a higher cumulative PD than from patients, but the difference was not statistically significant. The discrepancy between the two groups may be explained by the different median ages. In a previous study, in which we expanded donor MSCs for a median of 18 passages, we demonstrated that the cell growth of in vitro expanded MSCs is closely related to the donor's age (15), which tallies with other studies reporting a negative correlation between donor age and MSC proliferative potential $(7,21,28)$.

No correlation between the cellular expansion potential of MSCs and the duration or expansion potential and severity of the disease was found among patients. The discrepancy between the two groups may be explained by the different ages, as previously demonstrated by our group (15) and by other studies $(7,21,28)$.

The immunophenotype analysis revealed no significant differences between donors and patients for CD106 (vascular cell adhesion molecule 1, VCAM1), an adhesion molecule constitutively expressed by BM stromal cells that is important for the retention of hematopoietic precursor cells (HPC) in the hemopoietic organs during development (27), which seemed higher during expansion in patients' MSC. Moreover MSCs, both from healthy donors and from ALS patients, showed multilineage potential when cultivated in different conditioning media specific for osteogenic, adipogenic, and chondrogenic differentiation. As reported by Dominici et al. (8), plastic adhesion in standard culture conditions, the expression of specific surface markers, and the capability to differentiate into osteoblasts, adypocytes, and chondrocytes are the minimal criteria to define human MSCs. We also demonstrated that donor and patient MSCs acquired, under specific condition, new morphological

\section{FACING COLUMN}

Figure 6. Multilineage differentiation of donor and patient MSCs into osteoblasts (A, B, C, D), adipocytes (E, F), chondrocytes $(\mathrm{G}, \mathrm{H})$, and neural-like cells (I, J, L, M). The presence of calcium oxalates seen with Von Kossa staining showed the differentiation of either donor (A) and patient (B) MSCs into the osteoblast lineage. Masson Thrichrom Goldner staining showed the accumulation of collagen (green) in donor (C) and patient (D) MSCs. Adipogenesis was indicated by the presence of neutral lipid vacuoles in donor (E) and in patient (F) MSCs. Sections from paraffin-embedded pellets after chondrogenic induction resulted positive for S-100 staining in all samples analyzed $(\mathrm{G}, \mathrm{H})$. Donor MSCs cultured in NPMM formed adherent clusters with cells showing prominent processes that resulted positive for NSE (I) and MAP-2 (L); the nuclei were counterstained with DAPI (blue). Patient MSCs displayed the same features $(\mathrm{J}, \mathrm{M})$. Original magnification: $10 \times(\mathrm{G}, \mathrm{H}), 20 \times(\mathrm{A}, \mathrm{B}, \mathrm{C}, \mathrm{D}, \mathrm{I}, \mathrm{L}, \mathrm{J}, \mathrm{M})$, and $40 \times(\mathrm{E}, \mathrm{F})$. 
characteristics and neural markers that are suggestive of neural differentiation, as recently reported (16).

Extensive in vitro expansion of patient MSCs does not involve any other modification, chromosomal alterations, or cellular senescence, suggesting that MSCs can be isolated and expanded from ALS patient maintaining all the peculiar MSC characteristics.

Mesenchymal stem cells have been transplanted in different animal models of central nervous systems diseases with evidences of their capability to survive, proliferate, and migrate into the damaged tissue with positive functional effects (13). MSCs isolated from bone marrow are widely used in many human diseases because their potential to replicate as undifferentiated forms and to differentiate to multiple lineages (23) and their safety has been largely demonstrated (12).

Therefore, our data on the possibility of isolating functional MSCs from ALS patients the same as from healthy subjects suggest that MSCs might have a clinical use in ALS for cell-based therapy.

ACKNOWLEDGMENT: We are grateful to Andrew Martin Garvey, B.A. (Hons.) LTCL for editorial assistance.

\section{REFERENCES}

1. Bacigalupo, A.; Tong, J.; Podestà, M.; Piaggio, G.; Figari, O.; Colombo, P.; Sogno, G.; Tedone, E.; Moro, F.; Van Lint, M. T.; Frassoni, F.; Occhini, D.; Gualandi, F.; Lamparelli, T.; Marmont, A. M. Bone marrow harvest for marrow transplantation: Effect of multiple small $(2 \mathrm{ml})$ or large $(20 \mathrm{ml})$ aspirates. Bone Marrow Transplant. 9:467470; 1992.

2. Black, I.; Woodbury, D. Adult rat and human bone marrow stromal stem cells differentiate into neurons. Blood Cells Mol. Dis. 27:632-636; 2001.

3. Brooks, B. R.; Miller, R. G.; Swash, M.; Munsat, T. L. World Federation of Neurology Research Group on Motor Neuron Diseases. El Escorial revised criteria for the diagnosis of amyotrophic lateral sclerosis. Amyotroph. Lateral Scler. Other Motor Neuron Disord. 1:293-299; 2000.

4. Clement, A. M.; Nguyen, M. D.; Roberts, E. A.; Garcia, M. L.; Boillee, S.; Rule, M.; McMahon, A. P.; Doucette, W.; Siwek, D.; Ferrante, R. J.; Brown, Jr., R. H.; Julien, J. P.; Goldstein, L. S.; Cleveland, D. W. Wild-type nonneuronal cells extend survival of SOD1 mutant motor neurons in ALS mice. Science 302:113-117; 2003.

5. Corti, S.; Locatelli, F.; Donadoni, C.; Guglieri, M.; Papadimitriou, D.; Strazzer, S.; Del Bo, R.; Comi, G. P. Wildtype bone marrow cells ameliorate the phenotype of SOD1-G93A ALS mice and contribute to CNS, heart and skeletal muscle tissues. Brain 127:2518-2532; 2004.

6. Crigler, L.; Robey, R. C.; Asawachaicharn, A.; Gaupp, D.; Phinney, D. G. Human mesenchymal stem cell subpopulations express a variety of neuro-regulatory molecules and promote neuronal cell survival and neuritogenesis. Exp. Neurol. 198:54-64; 2006.

7. D'Ippolito, G.; Schiller, P. C.; Ricordi, C.; Roos, B. A.; Howard, G. A. Age-related osteogenic potential of mesenchymal stromal stem cells from human vertebral bone marrow. J. Bone Miner. Res. 14:1115-1122; 1999.
8. Dominici, M.; Le Blanc, K.; Mueller, I.; Slaper-Cortenbach, I.; Marini, F.; Krause, D.; Deans, R.; Keating, A.; Prockop, D. J.; Horwitz, E. Minimal criteria for defining multipotent mesenchymal stromal cells. The International Society for Cellular Therapy position statement. Cytotherapy 8:315-317; 2006.

9. Hemendinger, R.; Wang, J.; Malik, S.; Persinski, R.; Copeland, J.; Emerich, D.; Gores, P.; Halberstadt, C.; Rosenfeld, J. Sertoli cells improve survival of motor neurons in SOD 1 transgenic mice, a model of amyotrophic lateral sclerosis. Exp. Neurol. 196:235-243; 2005.

10. Jiang, Y.; Jahagirdar, B. N.; Reinhardt, R. L.; Schwartz, R. E.; Keene, C. D.; Ortiz-Gonzalez, X. R.; Reyes, M.; Lenvik, T.; Lund, T.; Blackstad, M.; Du, J.; Aldrich, S.; Lisberg, A.; Low, W. C.; Largaespada, D. A.; Verfaillie, C. M. Pluripotency of mesenchymal stem cells derived from adult marrow. Nature 418:41-49; 2002.

11. Kim, B. J.; Seo, J. H.; Bubien, J. K.; Oh, Y. S. Differentiation of adult bone marrow stem cells into neuroprogenitor cells in vitro. Neuroreport 13:1185-1188; 2002.

12. Koc, O. N.; Lazarus, H. M. Mesenchymal stem cells: Heading into the clinic. Bone Marrow Transplant. 27: 235-239; 2001.

13. Li, Y.; Chen, J.; Wang, L.; Zhang, L.; Lu, M.; Chopp, M. Intracerebral transplantation of bone marrow stromal cells in a 1-methyl-4-phenyl-1,2,3,6-tetrahydropyridine mouse model of Parkinson's disease. Neurosci. Lett. 316:67-70; 2001.

14. Mareschi, K.; Biasin, E.; Piacibello, W.; Aglietta, M.; Madon, E.; Fagioli, F. Isolation of human mesenchymal stem cells: Bone marrow versus umbilical cord blood. Haematologica 86:1099-1100; 2001.

15. Mareschi, K.; Ferrero, I.; Rustichelli, D.; Aschero, S.; Gammaitoni, L.; Aglietta, M.; Madon, E.; Fagioli, F. Expansion of mesenchymal stem cells isolated from pediatric and adult donor bone marrow. J. Cell Biochem. 97: 744-754; 2006

16. Mareschi, K.; Novara, M.; Rustichelli, D.; Ferrero, I.; Guido, D.; Carbone, E.; Medico, E.; Madon, E.; Vercelli, A.; Fagioli, F. Neural differentiation of human mesenchymal stem cells: Evidence for the expression of neural markers and eag $\mathrm{k}+$ channel types. Exp. Hematol. 34: 1563-1572; 2006.

17. Mazzini, L.; Fagioli, F.; Boccaletti, R.; Mareschi, K.; Oliveri, G.; Olivieri, C.; Pastore, I.; Marasso, R.; Madon, E. Stem cell therapy in amyotrophic lateral sclerosis: a methodological approach in humans. Amyotroph Lateral Scler Other Motor Neuron Disord. 4:158-161; 2003.

18. Mazzini, L.; Fagioli, F.; Boccaletti, R. Stem-cell therapy in amyotrophic lateral sclerosis. Lancet 364:1936-1937; 2004.

19. Mazzini, L.; Mareschi, K.; Ferrero, I.; Vassallo, E.; Oliveri, G.; Boccaletti, R.; Testa, L.; Livigni, S.; Fagioli, F. Autologous mesenchymal stem cells: Clinical applications in amyotrophic lateral sclerosis. Neurol. Res. 28: 523-526; 2006.

20. Morrison, K. E. Therapies in amyotrophic lateral sclerosis-beyond riluzole. Curr. Opin. Pharmacol. 2:302-309; 2002.

21. Nishida, S.; Endo, N.; Yamagiwa, H.; Tanizawa, T.; Takahashi, H. E. Number of osteoprogenitor cells in human bone marrow markedly decreases after skeletal maturation. J. Bone Miner. Metab. 17:171-177; 1999.

22. Norris, Jr., F. H.; Calanchini, P. R.; Fallat, R. J.; Panchari, 
S.; Jewett, B. The administration of guanidine in amyotrophic lateral sclerosis. Neurology 24:721-728; 1974.

23. Pittenger, M. F.; Mackay, A. M.; Beck, S. C.; Jaiswal, R. K.; Douglas, R.; Mosca, J. D.; Moorman, M. A.; Simonetti, D. W.; Craig, S.; Marshak, D. R. Multilineage potential of adult human mesenchymal stem cells. Science 284:143-147; 1999.

24. Rowland, L. P.; Shneider, N. A. Amyotrophic lateral sclerosis. N. Engl. J. Med. 344:1688-1700; 2001.

25. Rufer, N.; Dragowska, W.; Thornbury, G.; Roosnek, E.; Lansdorp, P. M. Telomere length dynamics in human lymphocyte subpopulations measured by flow cytometry. Nat. Biotechnol. 16:743-747; 1998.

26. Sanchez-Ramos, J.; Song, S.; Cardozo-Pelaez, F.; Hazzi, C.; Stedeford, T.; Willing, A.; Freeman, T. B.; Saporta, S.; Janssen, W.; Patel, N.; Cooper, D. R.; Sanberg, P. R. Adult bone marrow stromal cells differentiate into neural cells in vitro. Exp. Neurol. 164:247-256; 2000.

27. Schweitzer, C. M.; van der Schoot, C. E.; Drager, A. M.; van der Valk, P.; Zevenbergen, A.; Hooibrink, B.; Westra, A. H.; Langenhuijsen, M. M. Isolation and culture of human bone marrow endothelial cells. Exp. Hematol. 23:41$48 ; 1995$.
28. Stenderup, K.; Justesen, J.; Clausen, C.; Kassem, M. Aging is associated with decreased maximal life span and accelerated senescence of bone marrow stromal cells. Bone 33:919-926; 2003.

29. Terada, N.; Hamazaki, T.; Oka, M.; Hoki, M.; Mastalerz, D. M.; Nakano, Y.; Meyer, E. M.; Morel, L.; Petersen, B. E.; Scott, E. W. Bone marrow cells adopt the phenotype of other cells by spontaneous cell fusion. Nature 416: 542-545; 2002.

30. The ALS-CNTF treatment Study (ACTS) Phase I-II study group. The Amyotrophic Lateral Sclerosis functional rating scale: Assessment of activities of daily living in patients with amyotrophic lateral sclerosis. Arch. Neurol. 53: 141-147; 1996.

31. Woodbury, D.; Reynolds, K.; Black, I. B. Adult bone marrow stromal stem cells express germline, ectodermal, endodermal, and mesodermal genes prior to neurogenesis. J. Neurosci. Res. 69:908-917; 2002.

32. Woodbury, D.; Schwarz, E. J.; Prockop, D. J.; Black, I. B. Adult rat and human bone marrow stromal cells differentiate into neurons. J. Neurosi. Res. 61:364-370; 2000. 